\title{
Current issues on simultaneous TAVR (Transcatheter Aortic Valve Replacement) and EVAR (Endovascular Aneurysm Repair).
}

NIKOLAOS SCHIZAS ${ }^{1}$, Constantine N. Antonopoulos ${ }^{2}$, VASILEIOS PATRIS ${ }^{3}$, Konstantinos Lampropoulos ${ }^{4}$, Theodoros Kratimenos ${ }^{5}$, and Mihalis Argiriou ${ }^{3}$

${ }^{1}$ Evangelismos Athens General Hospital

${ }^{2}$ General Hospital of Athens "Evangelismos"

${ }^{3}$ EVAGELISMOS

${ }^{4} 251$ General Air force Hospital

${ }^{5}$ Evangelismos General Hospital

November 30, 2020

\begin{abstract}
Single-stage endovascular treatment of cardiac and vascular diseases with combined endovascular techniques has bee increasingly reported in the contemporary literature. Although more complex cases are currently being treated with such techniques, there are still crucial issues regarding their safety and efficacy.silmutaneous
\end{abstract}

\section{Hosted file}

Current_issues_on_simultaneous_TAVR_(Transcatheter_Aortic_Valve_Replacement)_and_EVAR_(Endovascular_Ane available at https://authorea.com/users/363299/articles/496092-current-issues-onsimultaneous-tavr-transcatheter-aortic-valve-replacement-and-evar-endovascular-aneurysmrepair 


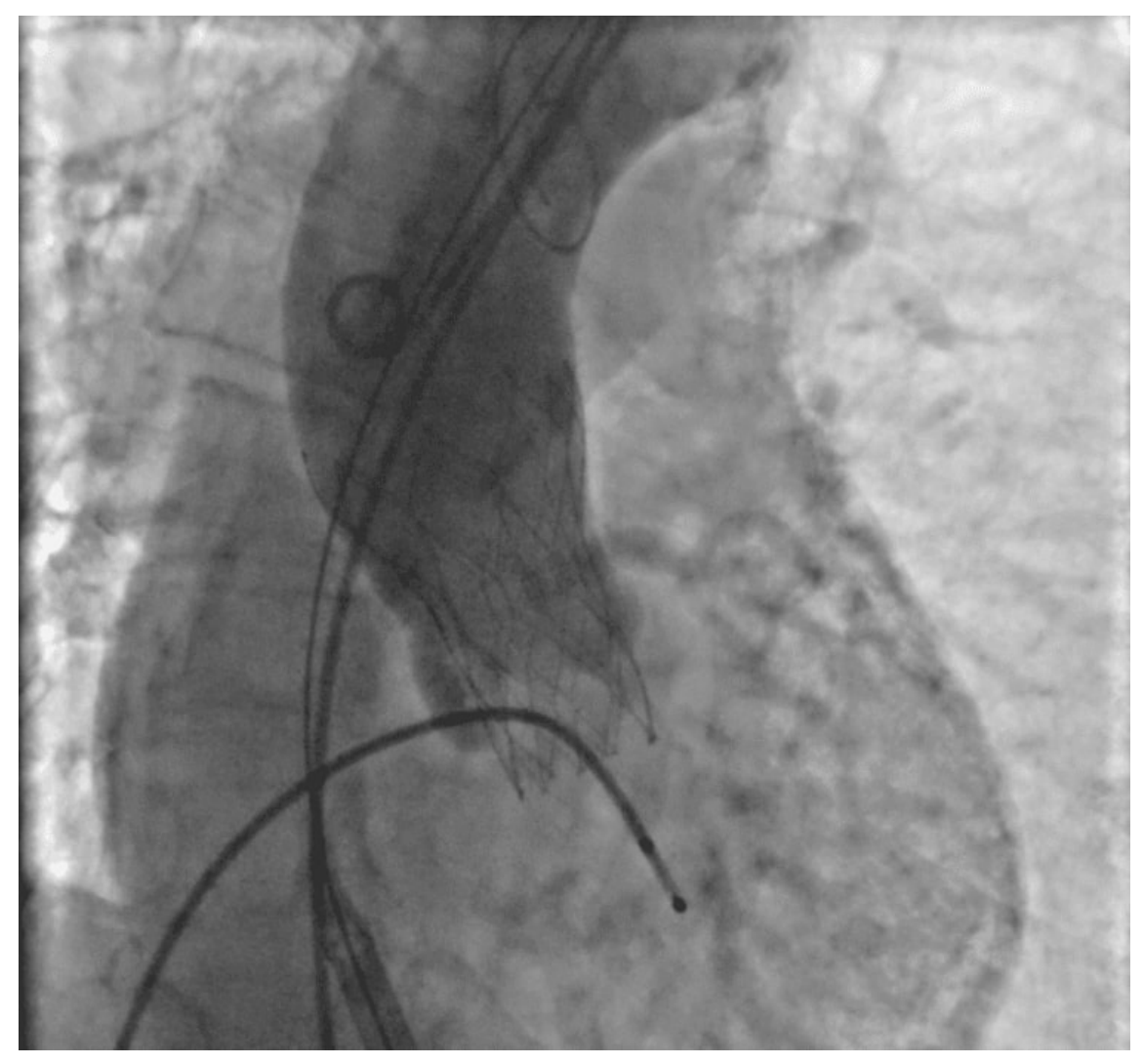




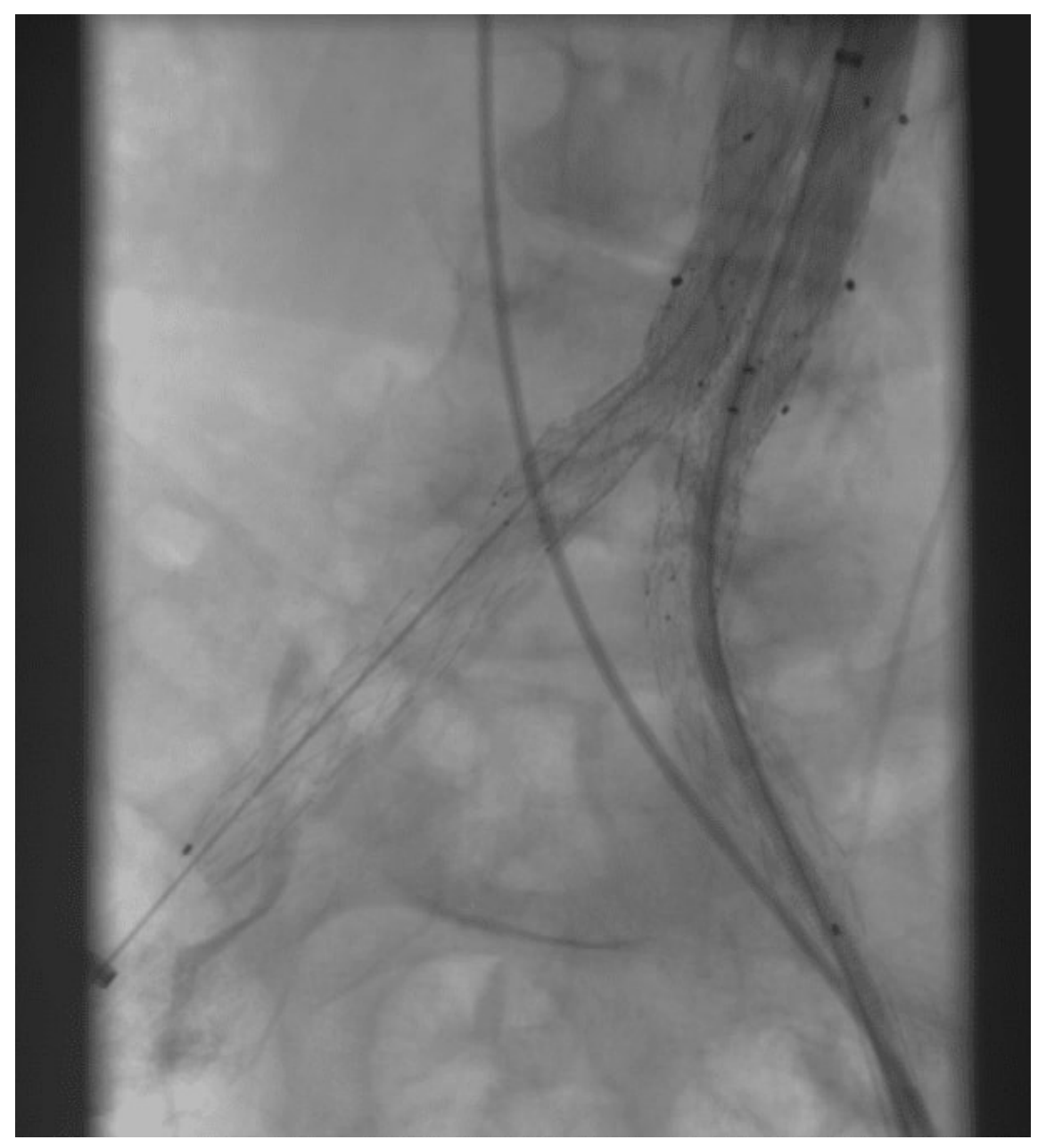




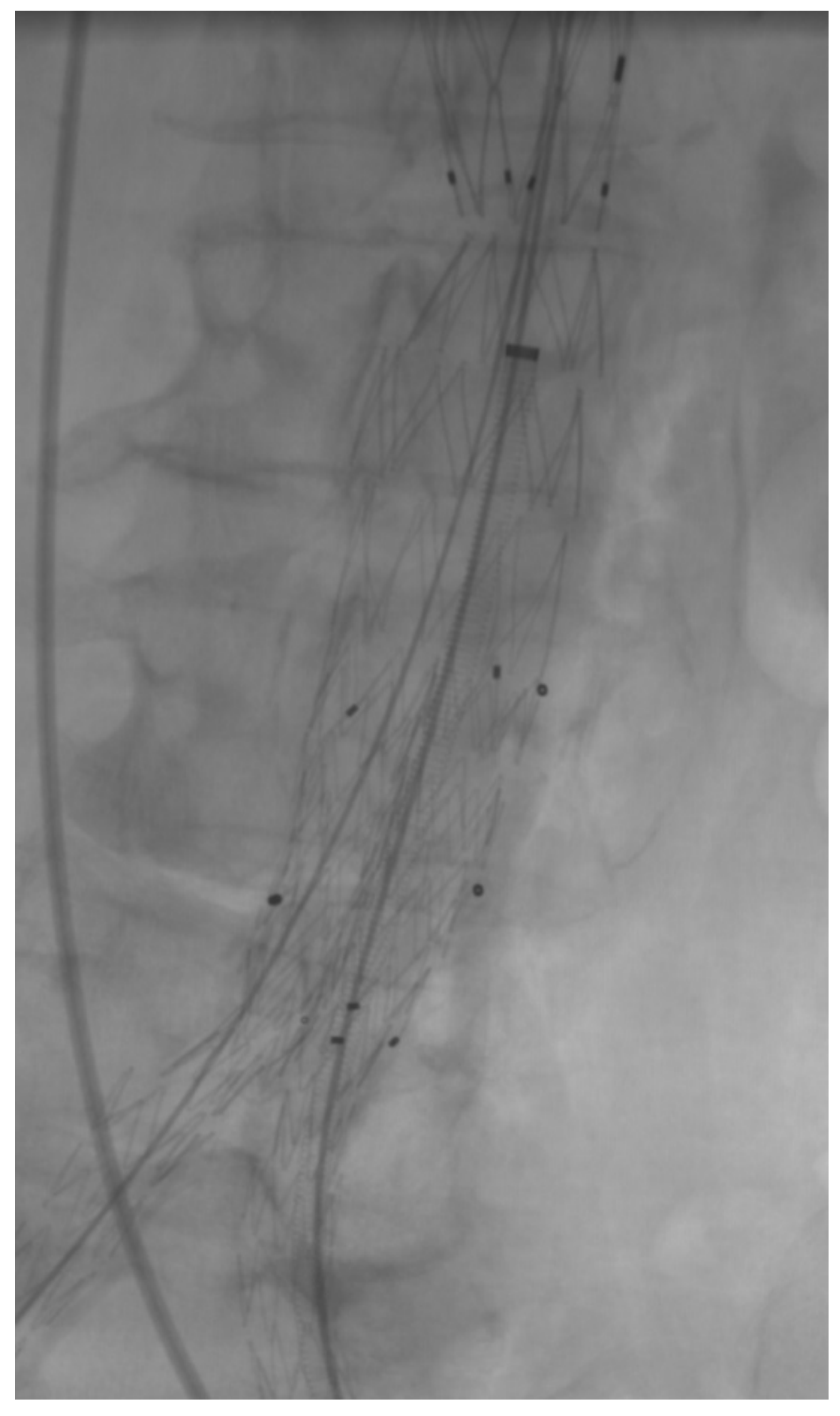

